ARTICLE

\title{
Controlled partial transfer hydrogenation of quinolines by cobalt-amido cooperative catalysis
}

Maofu Pang ${ }^{1}$, Jia-Yi Chen ${ }^{2}$, Shengjie Zhang ${ }^{1}$, Rong-Zhen Liao ${ }^{2 凶}$, Chen-Ho Tung $^{1} \&$ Wenguang Wang (1) ${ }^{1 凶}$

Catalytic hydrogenation or transfer hydrogenation of quinolines was thought to be a direct strategy to access dihydroquinolines. However, the challenge is to control the chemoselectivity and regioselectivity. Here we report an efficient partial transfer hydrogenation system operated by a cobalt-amido cooperative catalyst, which converts quinolines to 1,2-dihydroquinolines by the reaction with $\mathrm{H}_{3} \mathrm{~N} \cdot \mathrm{BH}_{3}$ at room temperature. This methodology enables the large scale synthesis of many 1,2-dihydroquinolines with a broad range of functional groups. Mechanistic studies demonstrate that the reduction of quinoline is controlled precisely by cobalt-amido cooperation to operate dihydrogen transfer from $\mathrm{H}_{3} \mathrm{~N} \cdot \mathrm{BH}_{3}$ to the $\mathrm{N}=\mathrm{C}$ bond of the substrates.

\footnotetext{
${ }^{1}$ Key Lab of Colloid and Interface Chemistry, Ministry of Education, School of Chemistry and Chemical Engineering, Shandong University, No. 27 South Shanda Road, Jinan 250100, P. R. China. ${ }^{2}$ School of Chemistry and Chemical Engineering, Huazhong University of Science and Technology, 1037 Luoyu Road, Wuhan 430074, China. ${ }^{凶}$ email: rongzhen@hust.edu.cn; wwg@sdu.edu.cn
} 
$\mathrm{D}$ ihydroquinolines (DHQs) are a potential surrogate of $\mathrm{H}_{2}$ for sustainable transformations, reminiscent of the structure of reduced nicotinamide adenine dinucleotide phosphate $(\mathrm{NADPH})^{1-4}$, More importantly, 1,2-DHQs are versatile synthons leading to bioactive molecules ${ }^{5}$, pharmaceuticals 6,7 , natural products ${ }^{8-10}$, and organic electroluminescent materials ${ }^{11}$. They can be conveniently transformed by $\mathrm{C}-\mathrm{H}$ functionalization ${ }^{12}$ to complex organic structures, and can achieve asymmetric olefin difunctionalization ${ }^{13,14}$, and $N$-functionalization ${ }^{15}$ (Fig. 1a). Catalytic regioselective hydrogenation and transfer hydrogenation of $N$-heteroarenes have attracted intense interest ${ }^{16-25}$, and could provide the most straightforward protocol with which to harvest the desired DHQs. However, catalytic transformation of quinolines to DHQs is extremely challenging.

Significant progress has been made in hydrogenation of quinolines to tetrahydroquinolines (THQs) ${ }^{26-29}$, and transfer hydrogenation reactions with formates ${ }^{30}$, alcohols ${ }^{31,32}$ or Hantzsch esters ${ }^{33-35}$ (Fig. 1b), but the related catalysis to access DHQs has not been revealed to date. The difficulty associated with such catalysis to access 1,2-DHQs is control of chemoselectivity and regioselectivity since these reactions always suffer from over-reduction of the more reactive DHQs to THQs ${ }^{16,36}$. The breakthrough in this field was catalytic hydrosilylation and hydroboration of quinolines to the $N$-silylated or $N$-borylated 1,2DHQs ${ }^{37-44}$ respectively, using transition metal catalysts or metalfree organocatalysts 45,46 . Deprotection of the silyl or boryl groups of the $N$-protected DHQs can provide an alternative route to 1,2DHQs, however, such an $\mathrm{N}$-protection/hydrolysis strategy encounter issues related to functional group compatibility and the complicated purification procedures ${ }^{39}$, which limits the expansion of 1,2-DHQ chemistry.

Synergism of metal-ligand reactivity is a practical strategy with which to design new catalysts to perform precise transformations $s^{47-54}$. For example, cooperative Ru-S reactivity allows for activation of the $\mathrm{Si}-\mathrm{H}$ bond of hydrosilanes and catalytic intermolecular electrophilic $\mathrm{C}-\mathrm{H}$ silylation of $\mathrm{N}$ protected indoles to afford the corresponding C3-silylated indoles as single regioisomers ${ }^{55-57}$. In particular, such metalligand cooperation strategy greatly promotes the utility of the abundant metals for hydrogenation and transfer hydrogenation of unsaturated hydrocarbons ${ }^{58-63}$. However, the related catalysis has not been reported for the direct synthesis of DHQs.

In this work, we report an efficient cobalt-amido cooperative catalyst for the controlled, partial transfer hydrogenation of

a Diverse functionalization of 1,2-DHQ

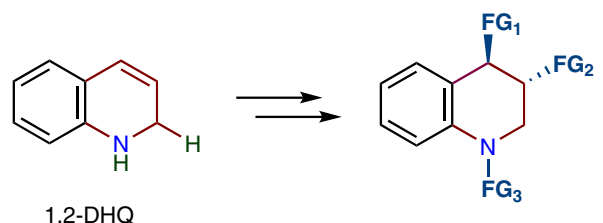

$1,2-\mathrm{DHQ}$

b Hydrogenation or transfer hydrogenation of quinolines to THQ (previous work)

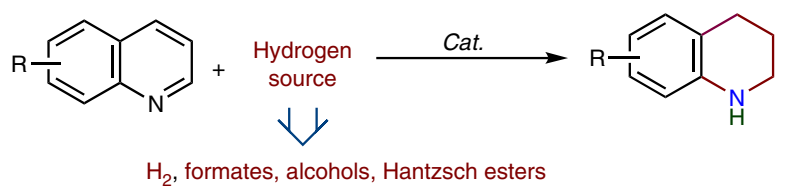

quinolines to 1,2-DHQs with $\mathrm{H}_{3} \mathrm{~N} \cdot \mathrm{BH}_{3}$ (Fig. 1c). Compared with the previous methods of catalytic hydrosilylation and hydroboration, the functional group tolerance in the present catalysis is exceedingly broad, in particular, with respect to ester, amide, and alkenyl moieties. Notably, tetrahydrogenation of the quinoline substrate can be also realized by using two equiv. of reducing agent under the identical reaction conditions for the catalytic dihydrogenation. Additionally, we have demonstrated that 1,2DHQs are valuable starting material to synthesize chiral THQs, and they can serve as reducing agent for dihydrogen transfer.

\section{Results}

Synthesis and reactivity of 1 . The phosphinoamido cobalt(II) half-sandwich complex (1) was easily prepared by treatment of $\left[\mathrm{Cp}^{*} \mathrm{CoCl}\right]_{2}$ with lithium (2-(diphenylphosphanyl)-4-methylphenyl)amide in $\mathrm{THF}^{64}$. Single crystal X-ray diffraction confirmed its structure as a neutral cobalt(II) compound with a 17electron configuration. This compound was initially found to react gently with $\mathrm{H}_{3} \mathrm{~N} \cdot \mathrm{BH}_{3}$, gradually releasing $\mathrm{H}_{2}$ at room temperature. In particular, $\mathbf{1}$ is capable of catalyzing this dehydrogenation reaction. With a catalyst loading of $0.5 \mathrm{~mol} \%$, a solution in THF of $\mathrm{H}_{3} \mathrm{~N} \cdot \mathrm{BH}_{3}$ in $10 \mathrm{~h}$ released a nearly equimolar quantity of $\mathrm{H}_{2}$ based on GC quantification (see Supplementary Fig. 1).

Partial transfer hydrogenation of 4-methylquinoline. Based on the reactivity of 1 toward $\mathrm{H}_{3} \mathrm{~N} \cdot \mathrm{BH}_{3}$, the transfer hydrogenation of 4-methylquinoline (2a) with $\mathrm{H}_{3} \mathrm{~N} \cdot \mathrm{BH}_{3}$ was examined using $\mathbf{1}$ as a catalyst (see Supplementary Table 1). With $5 \mathrm{~mol} \%$ of $\mathbf{1}$ in $d_{8^{-}}$ toluene, the reaction of the quinoline (2a) with 1.1 equiv of $\mathrm{H}_{3} \mathrm{~N} \cdot \mathrm{BH}_{3}$ was conducted in a Young NMR tube. According to the ${ }^{1} \mathrm{H}$ NMR spectroscopic analysis, the reaction conducted at $25^{\circ} \mathrm{C}$ provided 4-methyl-1,2-dihydroquinoline (3a) in 36\% yield in $4 \mathrm{~h}$. Control experiments indicated that the cobalt complex is responsible for the catalysis, no reaction being observed in the absence of 1. Remarkably, in THF the quinoline substrate was converted nearly quantitatively to $\mathbf{3 a}$ within $3 \mathrm{~h}$. This system is extremely effective; with even $0.5 \mathrm{~mol} \%$ of $\mathbf{1}$, the yield of $\mathbf{3 a}$ reaches $99 \%$ within $20 \mathrm{~h}$. Scaling up of the transfer hydrogenation failed to decrease the yield and pure $\mathbf{3 a}$ was isolated in $95 \%$ yield (see Fig. 2).

Using $0.5 \mathrm{~mol} \%$ of 1 in $\mathrm{THF}$ at $25^{\circ} \mathrm{C}$, under the optimized reaction conditions, we investigated the substrate scope for the

C Controlled transfer hydrogenation to $1,2-\mathrm{DHQ}$ (this work)
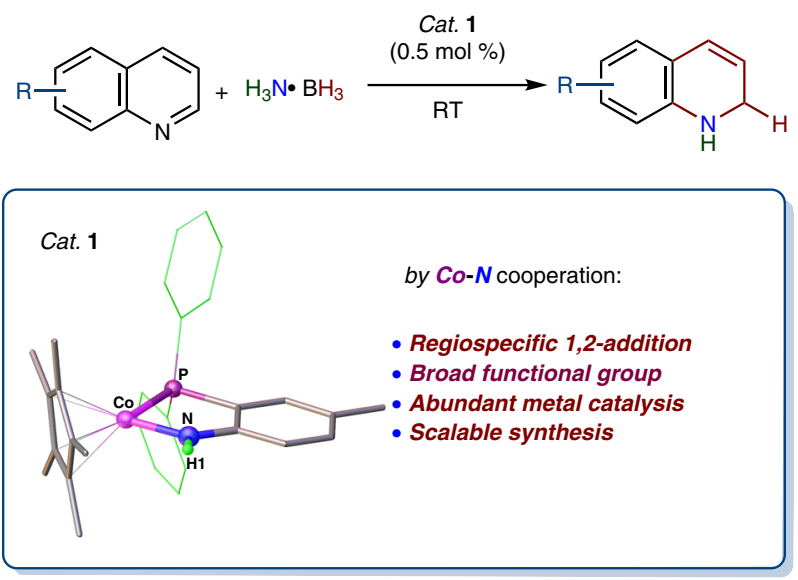

Fig. 1 Conversion of quinolines to THQs and 1,2-DHQs. a Diverse functionalization of 1,2-DHQ. $\mathbf{b}$ Hydrogenation and transfer hydrogenation of quinolines to THQs. c The present work on transfer hydrogenation of quinolines with $\mathrm{H}_{3} \mathrm{~N} \cdot \mathrm{BH}_{3}$ to 1,2-DHQs by a cobalt-amido cooperative catalyst. 


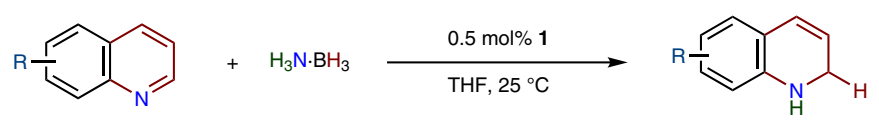<smiles>Cc1ccccc1</smiles>

3a, $95 \%$<smiles>C1=Cc2ccccc2NC1</smiles>

3b, $91 \%$<smiles>Brc1ccccc1</smiles>

3c, $86 \%$<smiles>ClC1=Cc2ccccc2NC1</smiles>

3d, $83 \%$<smiles>BrC1=Cc2ccccc2NC1</smiles>

3e, $80 \%$<smiles>OCC1=Cc2ccccc2NC1</smiles>

3f, $87 \%$<smiles>CCOC(=O)C1=Cc2ccccc2NC1</smiles>

$3 g, 93 \%$

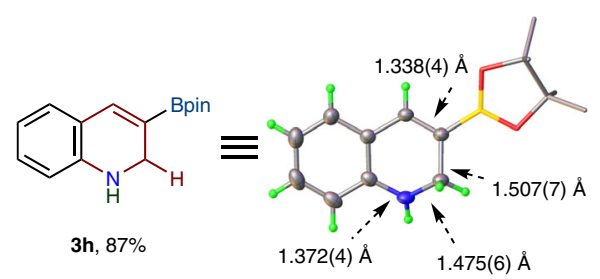<smiles>CC(O)C1C=Cc2ccccc2N1</smiles>

$3 \mathrm{~m}, 89 \%^{\mathrm{a}}$

CCDC: 1935439<smiles>CC1=Cc2ccccc2NC1</smiles>

3i, $90 \%$<smiles>CC(=O)NC1=Cc2ccccc2NC1</smiles>

3j, $88 \%$<smiles>Cc1cccc2c1C=CCN2</smiles>

3p, $81 \%(90: 10)^{\text {b }}$<smiles>C#CC1=Cc2ccccc2NC1</smiles>

3k, $86 \%$<smiles>Clc1cccc2ccccc12</smiles>

3q, $71 \%(96: 4)^{\text {b }}$<smiles>C1=C(/C=C/c2ccccc2)CNc2ccccc21</smiles>

3I, $84 \%$<smiles>C1=Cc2ccccc2NC1</smiles>

3o, $74 \%(96: 4)^{\mathrm{b}}$

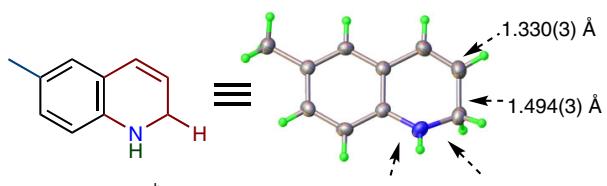

3u, 73\% (91:9) ${ }^{\text {b }}$
1.392(2) Å 1.456(2) $\AA$ CCDC: 1935440 3s, $88 \%(94: 6)^{\text {b }}$<smiles>C1=Cc2cc(Cc3ccccc3)ccc2NC1</smiles>

$3 x, 89 \%$<smiles>COc1ccc2c(c1)NCC=C2Cl</smiles>

3ad, $89 \%$<smiles>Cc1ccc2c(c1)NC(C)C=C2</smiles>

3y, $83 \%(90: 10)^{b}$<smiles>Clc1ccc2c(c1)NC(I)C=C2</smiles>

3z, $76 \%(96: 4)^{\mathrm{b}}$<smiles>[CH2]c1ccc2c(c1)NCC=C2</smiles>

3aa, 73\%<smiles>c1ccccc1</smiles>

3v, $84 \%(90: 10)$<smiles>Fc1ccc2c(c1)C(Cl)=CCN2</smiles>

3ab, $78 \%$

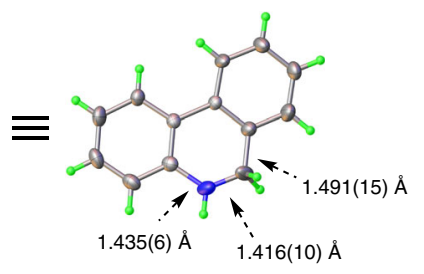<smiles>NC1C=Cc2cc(F)ccc2N1</smiles>

$3 r, 82 \%(90: 10)^{b}$

CCDC: 1935443<smiles>c1ccc2c(c1)NCS2</smiles>

3af, $86 \%$<smiles>c1ccc2c(c1)CNc1ccccc1-2</smiles>

3ag, 92\%<smiles>c1ccc2c(c1)NCO2</smiles>

3ae, $91 \%$

Fig. 2 Substrate scope. Reaction conditions: substrate $(0.5 \mathrm{mmol}), \mathrm{H}_{3} \mathrm{~N} \mathrm{BH}_{3}(0.55 \mathrm{mmol})$ and $\mathbf{1}(0.5 \mathrm{~mol} \%)$ were stirred in $\mathrm{THF}(2 \mathrm{~mL})$ at $25^{\circ} \mathrm{C}$ for $20 \mathrm{~h}$. Isolated yields are given. ${ }^{\mathrm{T}} \mathrm{T}$ wo equiv. of $\mathrm{H}_{3} \mathrm{~N} \cdot \mathrm{BH}_{3}(1 \mathrm{mmol})$ was used for reduction of 3-acetylquinoline. ${ }^{b} \mathrm{Ratios}$ in parentheses refer to product ratios of 1,2DHQ and THQ determined by ${ }^{1} \mathrm{H}$ NMR spectroscopy.

catalysis (Fig. 2). After changing the methyl group to a phenyl or bromo group, the corresponding 4 -substituted-1,2-DHQs $(\mathbf{3 b}, \mathbf{3 c})$ were obtained with good yields. Notably, quinolines with a variety of functional groups such as $\mathrm{Cl}$ (2d), $\mathrm{Br}(\mathbf{2 e}), \mathrm{CH}_{2} \mathrm{OH}$ (2f), $\mathrm{COOC}_{2} \mathrm{H}_{5}(\mathbf{2 g}), \mathrm{NHCOCH}_{3}(\mathbf{2 j}), \mathrm{Bpin}(\mathbf{2 h}), \mathrm{C}=\mathrm{CPh}(\mathbf{2 l})$ and $\mathrm{C} \equiv \mathrm{CPh}(\mathbf{2 k})$ at the 3-position all underwent smooth transfer hydrogenation to furnish the dearomatized products (3d-3l). The synthesis of 1,2-DHQs with ester substituents ( $\mathbf{3 g}$ and $\mathbf{3 h}$ ) or an amide group (3j) is challenging since they are prone to hydrolysis during the deprotection of the $\mathrm{N}$-silylated or $\mathrm{N}$-borylated dihydroquinoline precursors ${ }^{39}$. Unlike the ester groups, the acyl group was hydrogenated in the course of partial transfer hydrogenation of the $\mathrm{N}$-heterocycle. The reaction of 3acetylquinoline (2m) with two equiv of $\mathrm{H}_{3} \mathrm{~N} \cdot \mathrm{BH}_{3}$ produced the corresponding hydroxyl compound (3m) in $89 \%$ yield. The reduction of 2-methylquinoline failed, probably due to the steric effect on the 1,2-hydrogenation (3n $)^{41}$. Transfer hydrogenation of quinoline produced 1,2-DHQ (3o), which was obtained as solid.

In general, the regioselective 1,2-reduction of quinolines is not impeded by the electronic or steric nature of functional groups on the aryl ring. A variety of functionalized 1,2-DHQs (3p-3ad) were obtained in good to excellent yield with this mild catalytic protocol. In particular, halogen substituted quinolines tolerate the catalysis, as exemplified by $\mathbf{3 c}(86 \%), 3 \mathbf{d}(83 \%), \mathbf{3 e}(80 \%), \mathbf{3 q}$ (71\%), 3r (82\%), 3s (88\%), 3t (81\%), 3z (76\%), 3aa (73\%), 3ab (78\%), 3ac (81\%) and 3ad (89\%). Although cobalt-based transfer hydrogenations of alkynes and alkenes with $\mathrm{H}_{3} \mathrm{~N} \cdot \mathrm{BH}_{3}$ have been reported ${ }^{65,66}$, the dihydrogenation reaction occurs selectively at 
the $\mathrm{C}=\mathrm{N}$ bond of the $N$-heterocyclic ring (3k, 3l, and $3 \mathbf{v})$. This cobalt-based catalytic reaction is not limited only to quinolines, and it can also efficiently process the transfer hydrogenation of benzo[d]oxazole, benzothiazole, phenanthridine and acridine, providing the desired products (3ae-3ah) with excellent yields. This protocol is extremely efficient and most of 1,2-DHQs were conveniently synthesized on a large scale and purified by crystallization. Crystal structures of $\mathbf{3 h}, \mathbf{3} \mathbf{u}$ and $\mathbf{3 a g}$ were unequivocally established by single-crystal X-ray diffraction (Fig. 2). In the dihydrogenation of quinolines with substituents on the phenyl ring, THQs were also observed as by-products $(<10 \%$ yield) which arise from further reduction of the resultant 1,2-DHQs (see below).

Transfer hydrogenation to THQs. DHQs are presumed to be key intermediates in the hydrogenation of quinolines to THQs ${ }^{16}$. Indeed, 1,2-DHQs can be smoothly further reduced to THQs by $\mathrm{H}_{3} \mathrm{~N} \cdot \mathrm{BH}_{3}$ in the presence of the cobalt catalyst. For example, the 6-methyldihydroquinoline (3u) was completely converted to the tetrahydrogenated product $(\mathbf{4 u})$ under the catalytic conditions. Use of two equiv of $\mathrm{H}_{3} \mathrm{~N} \cdot \mathrm{BH}_{3}$ under the identical conditions of partial reduction allowed the transfer hydrogenation of $2 \mathbf{u}$ to $4 \mathbf{u}$ with an excellent yield. To compare the differences in bond distances and angles between dihydrogenated and tetrahydrogenated quinolines, the structures of $\mathbf{3 u}$ and $\mathbf{4} \mathbf{u}$ were superimposed as shown in Fig. 3. Comparing $\mathbf{3 u}$ with $\mathbf{4} \mathbf{u}$ reveals significant differences in the heterocyclic ring of the compounds. As a result of the second reduction the $\mathrm{C} 2-\mathrm{C} 3$ distance increases from 1.330(3) $\AA$ to $1.527(3) \AA$, and the N-heterocyclic ring becomes puckered.

Synthetic applications. As a partially saturated heteroaromatic compound, the 1,2-dihydroquinoline system could act as both hydride acceptor and hydride donor, resembling the oxidized and reduced nicotinamide adenine dinucleotide respectively. We found 1,2-DHQs can be employed as dihydrogen sources for sustainable transformations. For example, phenanthridine (2ag) is reduced to 5,6 -dihydrophenanthridine ( $3 \mathbf{a g}$ ) quantitatively by $3 \mathbf{u}$ in the presence of $3 \mathrm{~mol} \%$ of $\mathrm{CF}_{3} \mathrm{COOH}$ (TFA), and acridine (2ah) is hydrogenated to 9,10-dihydroacridine (3ah) by $\mathbf{3 u}$ under the identical reaction conditions (Fig. 4a). Disproportionation of $\mathbf{3 u}$ was not observed during the acid-catalyzed H-transfer reaction. The reaction profile monitored by ${ }^{1} \mathrm{H}$ NMR spectroscopy clearly showed that the increase in the concentration of $3 \mathrm{ah}$ over time is consistent with the consumption of $\mathbf{3 u}$ (Fig. 4b). Interestingly, $\mathbf{3 u}$ is stable toward 2, 6-dimethylpyridine-3, 5-dicarboxylate. These results demonstrate that $\mathbf{3 u}$ is a mild organo-hydride reagent, and its hydride-donating ability $\left(\Delta H_{\mathrm{H}_{-}}\right)$is weaker than that of the Hantszch ester $\left(\Delta H_{\mathrm{H}}{ }^{-}=69.3 \mathrm{kcal} / \mathrm{mol}\right)^{67}$.

1,2-DHQs are important synthetic intermediates that can lead to versatile $N$-heterocyclic compounds, such as chiral THQs and $N$-functionalized DHQs, which are common in pharmaceuticals and natural products ${ }^{68}$. For instance, through acylation and enantioselective borylation ${ }^{69}$, 6-trifluoromethyl-dihydroquinoline (3aa) was conveniently transformed to enantioenriched 3-boryltetrahydroquinolines $R-6$ ( $92 \%$ yield, $94 \%$ ee) and $S-6$ ( $87 \%$ yield, $95 \%$ ee), respectively (Fig. 4c). Such chiral $N$-heterocyclic organoboron compounds are amenable to diverse stereospecific functionalization at the stereogenic $\mathrm{C}-\mathrm{B}$ bond ${ }^{70,71}$. For example, subsequent amination of the two enantiomers allows for the construction of a new C-N bond ${ }^{72}$, affording $R-7$ and $S-7$ compounds without loss of enantiomeric purity ( $94 \%$ ee). In particular, enantiomer $S-7$ is a structural analog of positive inotropic agent $(S)-903$, and the potential agent Sumanirole for the treatment of Parkinson's disease ${ }^{73}$.

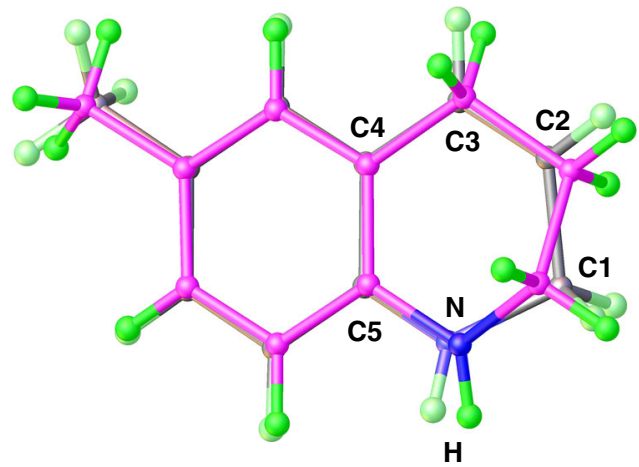

Fig. 3 Superposition of $\mathbf{3 u}$ (gray) with $\mathbf{4 u}$ (magenta). Selected bond distances $(\AA)$ for $\mathbf{4 u}$ : N1-C1, 1.452(3); C1-C2, 1.514(3); C2-C3, 1.527(3); C5-N1, 1.398 (3).

\section{Discussion}

To probe the mechanism of quioline reduction, the regiospecificity of hydrogen transfer with the selectively deuterated ammonia borane derivatives $\mathrm{D}_{3} \mathrm{~N} \cdot \mathrm{BH}_{3}$ and $\mathrm{H}_{3} \mathrm{~N} \cdot \mathrm{BD}_{3}$ was investigated for $2 \mathbf{u}$ (Fig. 5). Tracing the regioselectivity of the deuterium addition to $2 \mathbf{u}$ with $\mathrm{D}_{3} \mathrm{~N} \cdot \mathrm{BH}_{3}$, deuterium incorporation at the 1-position, the $\mathrm{N}$ atom in the desired product $(d-3 \mathbf{u})$ was found (see Supplementary Fig. 2). In the case of $\mathrm{H}_{3} \mathrm{~N} \cdot \mathrm{BD}_{3}$ as the dihydrogen source, ${ }^{2} \mathrm{H}$ NMR spectroscopic analysis established that $d$-3 $\mathbf{u}^{\prime}$ was D-labeled entirely at the 2-position. Consecutive regioselective transfer hydrogenation of $2 \mathbf{u}$ with two equiv of $\mathrm{D}_{3} \mathrm{~N} \cdot \mathrm{BH}_{3}$ afforded the bis-deuterated quinoline $\left(d_{2}-\mathbf{4 u}\right)$ deuterated at the 1- and 3-positions (Supplementary Fig. 4). In comparison with $d_{2}-4 \mathbf{u}$, the reaction of $2 \mathbf{u}$ with 2 equiv of $\mathrm{H}_{3} \mathrm{~N} \cdot \mathrm{BD}_{3}$ resulted in formation of $d_{2}-\mathbf{4} \mathbf{u}^{\prime}$ which has deuterium exclusively at the 2- and 4-positions.

To understand the relationship between the dihydrogenation and tetrahydrogenation catalysis performed by $\mathbf{1}$, we followed the kinetics of the reactions of 6-methylquinoline $(\mathbf{2 u})$ with one or two equiv of $\mathrm{H}_{3} \mathrm{~N} \cdot \mathrm{BH}_{3}$. The changes in concentrations of reaction components over time are shown in Fig. 6. Using one equiv of $\mathrm{H}_{3} \mathrm{~N} \cdot \mathrm{BH}_{3}$ as the hydrogen source, the reaction profile indicates that the dihydroproduct $(\mathbf{3 u})$ alone was produced in the initial period of transfer hydrogenation (Fig. 6a). Although $7 \%$ of tetrahydrogenated product $(\mathbf{4 u})$ was observed, the major product of the reaction was the dihydrogenated compound ( $3 \mathbf{u})$. In contrast, when starting with two equiv of $\mathrm{H}_{3} \mathrm{~N} \cdot \mathrm{BH}_{3}$, both $3 \mathbf{u}$ and $4 \mathbf{u}$ were produced in the initial stage of the catalysis but the reaction profile unambiguously reveals the intermediacy of $\mathbf{3 u}$ in the tetrahydrogenation reaction (Fig. 6b).

The kinetic order in each reaction component was established for the transformation of $2 \mathbf{u}$ to $3 \mathbf{u}$ at $25^{\circ} \mathrm{C}$. For reactions carried out at constant $[2 \mathbf{u}]$, i.e. $\left[\mathrm{H}_{3} \mathrm{~N} \cdot \mathrm{BH}_{3}\right]=0.32 \mathrm{M}$, the initial rate $\left(v_{\mathrm{i}}\right)$ for the product formation against the concentration of catalyst varied between 0.8 and $4.8 \mathrm{mM}$ and showed first-order kinetics in [1], leading to a rate constant, $k_{\mathrm{obs}}=4 \mathrm{M} \mathrm{min}^{-1}$ (Supplementary Fig. 5). At constant $\left[\mathrm{H}_{3} \mathrm{~N} \cdot \mathrm{BH}_{3}\right]=0.32 \mathrm{M}$ and $[\mathbf{1}]=1.6 \mathrm{mM}$, performing the dihydrogenation reaction with concentrations of $2 \mathrm{u}$ ranging from 0.16 to $0.64 \mathrm{M}$ led to a linear increase in $v_{\mathrm{i}}$ (Supplementary Fig. 6), which leads to a first-order reaction rate constant of $3.7 \mathrm{M} \mathrm{min}^{-1}$. This value is consistent with $k_{\text {obs }}$ deduced from the plot of $v_{\mathrm{i}} \sim[\mathbf{1}]$. No inhibition was observed for $v_{\mathrm{i}}$ at high initial concentrations of the substrate. Since $2 \mathbf{u}$ can be easily reduced to $4 \mathbf{u}$ at high concentrations of $\mathrm{H}_{3} \mathrm{~N} \cdot \mathrm{BH}_{3}$, the kinetic experiments were carried out at constant $[2 \mathbf{u}]=0.32 \mathrm{M}$ and $[\mathbf{1}]=1.6 \mathrm{mM}$ by varying $\left[\mathrm{H}_{3} \mathrm{~N} \cdot \mathrm{BH}_{3}\right]$ in the range of 0.08-0.32 M. A linear plot of $v_{\mathrm{i}} \sim\left[\mathrm{H}_{3} \mathrm{~N} \cdot \mathrm{BH}_{3}\right]$ established a 
a Sustainable dihydrogen transformation

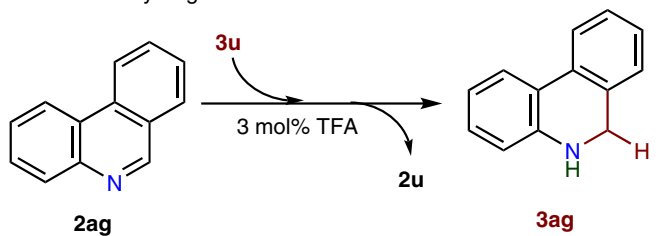

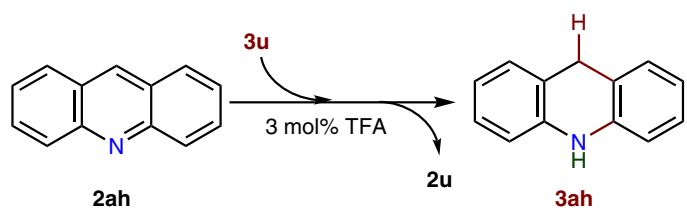

b

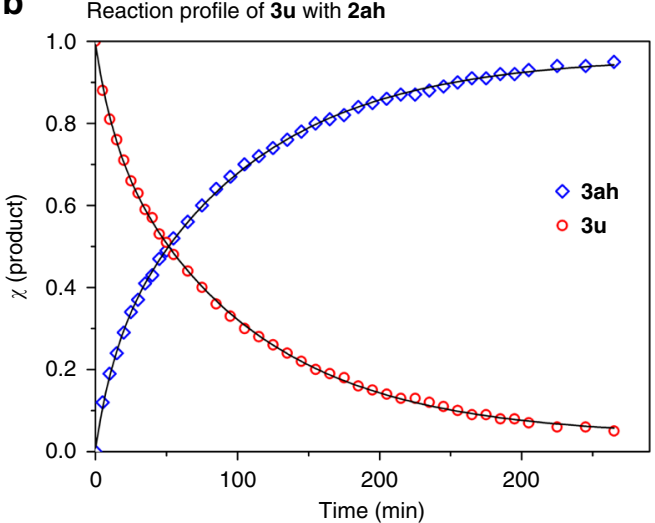

C Representative transformations to chiral THQs

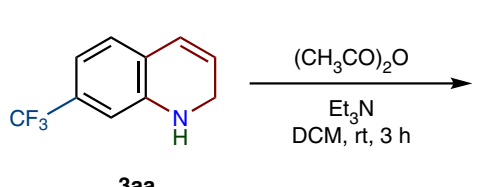

3aa<smiles>CC(=O)N1CC=Cc2ccc(C(F)(F)F)cc21</smiles>

5

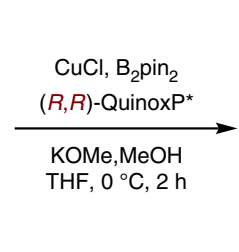

CuCl, $B_{2}$ pin $_{2}$
$(S, S)$-QuinoxP*

$\mathrm{KOMe}, \mathrm{MeOH}$

$\mathrm{THF}, 0^{\circ} \mathrm{C}, 2 \mathrm{~h}$

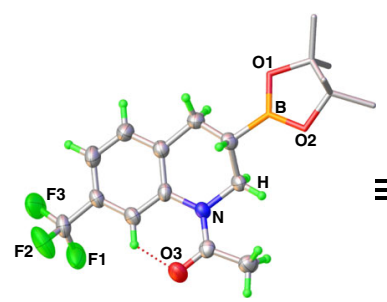

CCDC: 1970226<smiles>CC(=O)N1C[C@H]([18OH])Cc2ccc([13F])cc21</smiles>

S-6

$87 \%$ Yield, $95 \%$ ee

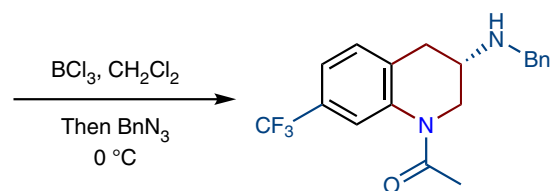

S-7

$65 \%$ Yield, $95 \%$ ee

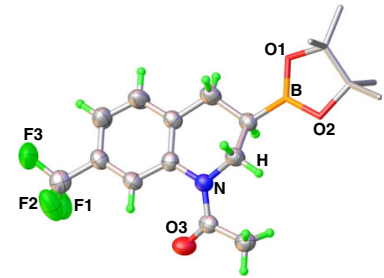

CCDC: 1970225
R-7

$68 \%$ Yield, $94 \%$ ee

Fig. 4 Synthetic Applications. a 3u serving as reducing agent for dihydrogen transfer. b Reaction profile of transfer hydrogenation of acridine (2ah, 0.32 $\mathrm{M})$ to 9,10 -dihydroacridine (3ah) by $\mathbf{3} \mathbf{u}\left(0.32 \mathrm{M}\right.$ ) catalyzed by $\mathrm{CF}_{3} \mathrm{COOH}(3 \mathrm{~mol} \%)$ in $\mathrm{THF}-d_{8}$ at $25^{\circ} \mathrm{C}$. c Asymmetric functionalization of $\mathbf{3 a a}$ through enantioselective borylation and amination.

a<smiles>Cc1ccc2c(c1)C=CCC2[Nb]</smiles>

d-3u

b

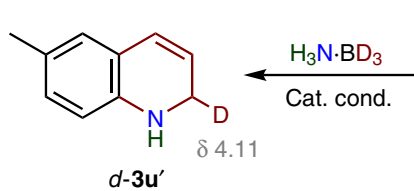<smiles>Cc1ccc2ncccc2c1</smiles>

$2 \mathrm{u}$<smiles>Cc1ccc2ncccc2c1</smiles>

Fig. 5 Deuterium labeling experiments. a Reactions of $\mathbf{2} \mathbf{u}$ with $\mathrm{D}_{3} \mathrm{~N} \cdot \mathrm{BH}_{3}$. b Reactions of $\mathbf{2} \mathbf{u}$ with $\mathrm{H}_{3} \mathrm{~N} \cdot \mathrm{BD}_{3}$.

first-order dependence on the dihydrogen source at this stage (Supplementary Fig. 7). These results indicate that all the three components are involved in the turnover-limiting formation of 3u. The overall rate law of this dihydrogenated reaction is thus expressed by rate $=k_{\text {obs }}[\mathbf{1}][2 \mathbf{u}]\left[\mathrm{H}_{3} \mathrm{~N} \cdot \mathrm{BH}_{3}\right]$.

Deuterium kinetic isotope effects (DKIE) were further probed for the dihydrogenation reaction (Supplementary Fig. 8).
According to the rate of formation of $3 \mathbf{u}$ measured for $\mathrm{H}_{3} \mathrm{~N} \cdot \mathrm{BH}_{3}$ versus $\mathrm{H}_{3} \mathrm{~N} \cdot \mathrm{BD}_{3}$, a KIE of $k_{\mathrm{NH} \cdot \mathrm{BH}} / k_{\mathrm{NH} \cdot \mathrm{BD}}=1.55$ was calculated. A larger KIE with $k_{\mathrm{NH} \cdot \mathrm{BH}} / k_{\mathrm{ND} \cdot \mathrm{BH}}=3.63$ was found for $2 \mathbf{u}$ with $\mathrm{D}_{3} \mathrm{~N} \cdot \mathrm{BH}_{3}$. For the double DKIE reaction of $\mathrm{D}_{3} \mathrm{~N} \cdot \mathrm{BD}_{3}$ with $2 \mathbf{u}$, the $\mathrm{KIE}$ value was determined to be $5.73\left(k_{\mathrm{NH} \cdot \mathrm{BH}} / k_{\mathrm{ND} \cdot \mathrm{BD}}\right)$. These results indicate that hydrogen transfers clearly participate in the turnover-determining step. 

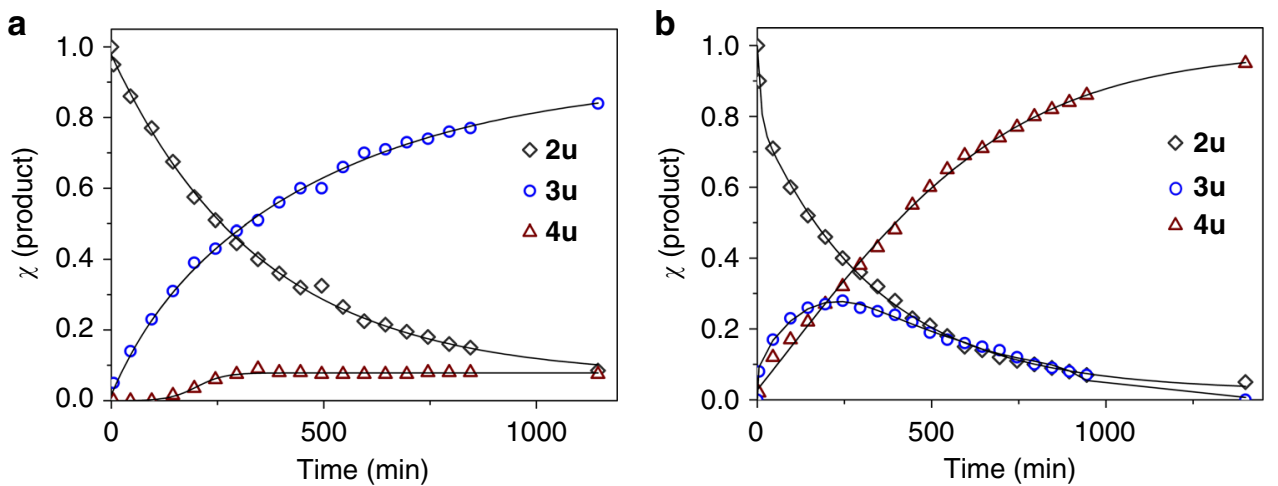

Fig. 6 Reaction profiles. a Catalytic transfer hydrogenations of 6-methylquinoline (2u) with one equiv of $\mathrm{H}_{3} \mathrm{~N} \cdot \mathrm{BH}_{3}$. b $\mathbf{2} \mathbf{u}$ with two equiv of $\mathrm{H}_{3} \mathrm{~N} \cdot \mathrm{BH}$. Conditions: $[\mathbf{2 u}]=0.32 \mathrm{M},[\mathbf{1}]=0.0016 \mathrm{M},\left[\mathrm{H}_{3} \mathrm{~N} \cdot \mathrm{BH}_{3}\right]=0.35 \mathrm{M}$ for (a) and $0.70 \mathrm{M}$ for $(\mathbf{b})$ in THF- $d_{8}$ at $25^{\circ} \mathrm{C}$.

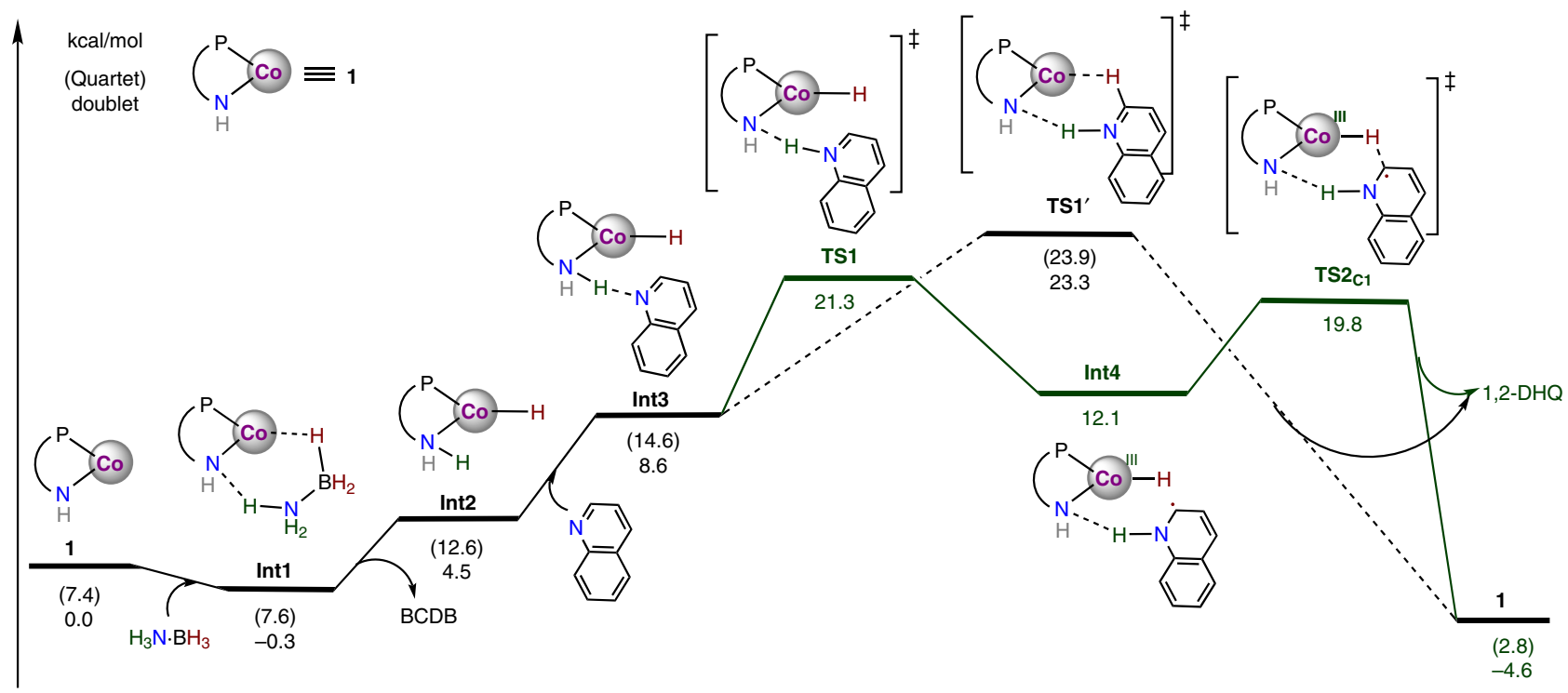

Fig. 7 Gibbs energy diagram. For computational details, see Supplementary Information.

Density functional calculations ${ }^{74}$ were performed to explore the detailed mechanism and regioselectivity of the reaction. As a 17-electron neutral compound, the catalyst (1) favors the low spin doublet, which is $7.4 \mathrm{kcal} / \mathrm{mol}$ lower in energy than the quartet state (Fig. 7). These calculations suggest that the catalysis is initiated by the reaction of 1 with $\mathrm{H}_{3} \mathrm{~N} \cdot \mathrm{BH}_{3}$ through an isoenergetic complex intermediate (Int1), in which a hydrogen bond $\mathrm{N}^{\mathrm{H}}---\mathrm{H}-\mathrm{NH}_{2}$ is formed by the interaction of the amide group with the $\mathrm{NH}_{3}$ moiety. A concerted proton transfer/hydride transfer ${ }^{75-77}$ from $\mathrm{H}_{3} \mathrm{~N} \cdot \mathrm{BH}_{3}$ to the amido-cobalt unit in Int1 yields a cobalt(II)-hydride species (Int2) by release of $\mathrm{H}_{2} \mathrm{~N}-\mathrm{BH}_{2}$. This step was calculated to be endergonic by $4.8 \mathrm{kcal} / \mathrm{mol}$ in the doublet state. Binding of the substrate to Int2 forming Int3, was predicted to proceed via $\mathrm{H}$-bonding between the $\mathrm{N}$ atom of the quinoline and the $\mathrm{H}$ atom of amino group of the ligand.

From Int3, four different mechanistic pathways have been located, and the two with lower barriers are presented here. The first of these involves proton transfer from the amino group to the quinoline nitrogen (TS1) coupled with an electron transfer from the $\mathrm{Co}^{\mathrm{II}}$ center to the quinoline moiety. TS1 is a doublet whose barrier was calculated to be $12.7 \mathrm{kcal} / \mathrm{mol}$ relative to Int3. The resultant $\mathrm{Co}^{\mathrm{III}}-\mathrm{H}$ species with an $\mathrm{N}$-hydrogenated quinoline radical (Int4) is $+3.5 \mathrm{kcal} / \mathrm{mol}$ higher in energy than Int3. Due to the directing effect of the hydrogen bond, $\mathrm{C}_{8} \mathrm{H}_{7} \mathrm{~N}---\mathrm{H}-\mathrm{N}^{\mathrm{H}}$ between the substrate and the amino group of the ligand, the hydrogen atom transfer from the metal center to the orthoposition of the substrate via $\mathbf{T S} \mathbf{2}_{\mathbf{C} \mathbf{1}}$ (1,2-hydrogenation pathway, $19.8 \mathrm{kcal} / \mathrm{mol}$ ) was found to be preferred by $2.3 \mathrm{kcal} / \mathrm{mol}$ over the $\mathrm{H}$-transfer to the para-position (TS2 $\mathrm{C3}, 1,4$-hydrogenation pathway, $22.1 \mathrm{kcal} / \mathrm{mol}$, Supplementary Fig. 99). TS1 was calculated to be the turnover-determining transition state (TDTS) with a total barrier of $21.6 \mathrm{kcal} / \mathrm{mol}$ relative to Intl (the turnover determining intermediate or TDI ${ }^{77}$. The calculated barrier is also in reasonable agreement with the experimental rate constant of 4 $\min ^{-1}$, which can be converted by classical transition state theory to an energy barrier of $19.0 \mathrm{kcal} / \mathrm{mol}$. Importantly, TS2 is the regioselectivity determining step and the regioselectivity is kinetically controlled. As a consequence, 1,2-DHQ is the major product, with a calculated product ratio 1,2-/1,4-DHQ of 48.6:1.

Such a stepwise $\mathrm{H}^{+}-\mathrm{e}^{-} / \mathrm{H}$. pathway can only take place in the doublet state, while in the quartet state the hydrogen transfers proceed via a concerted $\mathrm{H}^{+} / \mathrm{H}^{-}$pathway (TS1'). The concerted transfer of the hydridic $\mathrm{Co}(\mathrm{III})-\mathrm{H}$ and the protic $\mathrm{N}^{\mathrm{H}}-\mathrm{H}$ to the $\mathrm{C}=\mathrm{N}$ bond in the doublet state is energetically slightly favorable $(+0.6 \mathrm{kcal} / \mathrm{mol})$ over the quartet state. Related to the stepwise pathway, the total barrier of the concerted pathway is $2.0 \mathrm{kcal} / \mathrm{mol}$ higher. For both pathways, the ammonia proton is transferred to the quinoline nitrogen and the hydride of the $\mathrm{BH}_{3}$ unit is delivered to the 2-position of quinoline. This agrees well with the results obtained from deuterium isotope labeling experiments 
(Fig. 5). Other mechanisms through different $\mathrm{H}_{3} \mathrm{~N} \cdot \mathrm{BH}_{3}$ activation modes have also been considered (Supplementary Figs. 100-108), but are associated with much higher barriers.

DFT predictions imply a stepwise $\mathrm{H}^{+}-\mathrm{e}^{-} / \mathrm{H}$. pathway for the partial transfer hydrogenation. To gain more evidence, we calculated the kinetic isotope effects of deuterated ammonia boranes on the transition states of TS1, TS2 ${ }_{\mathbf{C 1}}$, and TS1' (Table 1). The calculated DKIE effects for TS1 using $\mathrm{H}_{3} \mathrm{~N} \cdot \mathrm{BD}_{3}$ or $\mathrm{D}_{3} \mathrm{~N} \cdot \mathrm{BH}_{3}$ are 3.57 and 1.67, respectively. Since TS1 involves a proton-coupled electron transfer process, it is reasonable that a larger KIE should come from deuterated $\mathrm{D}_{3} \mathrm{~N} \cdot \mathrm{BH}_{3}$ with respect to $\mathrm{H}_{3} \mathrm{~N} \cdot \mathrm{BD}_{3}$. The DKIE effect observed for $\mathrm{H}_{3} \mathrm{~N} \cdot \mathrm{BD}_{3}$ is dominated by an equilibrium isotope effect, resulting from the formation of a Co-D bond in Int 2 when compared with the B-D bond in Int1. For the double DKIE reaction of $\mathrm{D}_{3} \mathrm{~N} \cdot \mathrm{BD}_{3}$, the total KIE was predicted to be 6.01. Compared with the transition state of TS1, TS2 $2_{\mathrm{C} 1}$ was found to exhibit a much larger DKIE of 3.21 using $\mathrm{H}_{3} \mathrm{~N} \cdot \mathrm{BD}_{3}$ and only an equilibrium isotope effect (1.36) for $\mathrm{D}_{3} \mathrm{~N} \cdot \mathrm{BH}_{3}$. These DKIEs arise from transferring a deuterium atom from Co-D to $\mathrm{C} 1$, and the formation of N-D versus N-H bonds in $\mathrm{TS}_{\mathrm{C}}$ and Int1. In contrast, the DKIE increases to 6.09 when $\mathrm{D}_{3} \mathrm{~N} \cdot \mathrm{BH}_{3}$ is used in the concerted pathway involving TS1' while an inverse KIE of 0.50 was calculated for $\mathrm{H}_{3} \mathrm{~N} \cdot \mathrm{BD}_{3}$. The calculated DKIE values for TS2 $_{\mathbf{C} 1}$ and TS1' are inconsistent with the experimental results.

The calculated DKIE values for TS1 are consistent with the experimental values ( 1.55 for $\mathrm{H}_{3} \mathrm{~N} \cdot \mathrm{BD}_{3}, 3.63$ for $\mathrm{D}_{3} \mathrm{~N} \cdot \mathrm{BH}_{3}$, and 5.73 for $\mathrm{D}_{3} \mathrm{~N} \cdot \mathrm{BD}_{3}$ ), and this validates the suggested reaction pathway via TS1 as the TDTS. Accordingly, a proposed mechanism of the catalytic partial transfer hydrogenation of quinoline is shown in Fig. 8. Complemented by the basic site, the cobalt-amido complex $\left(\mathrm{Co}-\mathrm{N}^{\mathrm{H}}\right)$ is able to activate $\mathrm{H}_{3} \mathrm{~N} \cdot \mathrm{BH}_{3}$, generating a hydride-proton species $\left(\mathrm{HCo}-\mathrm{N}^{\mathrm{H}}(\mathrm{H})\right.$, Int2) for hydrogen transfers ${ }^{75-77}$. Combining the experimental data with theoretical studies, a stepwise $\mathrm{H}^{+}-\mathrm{e}^{-} / \mathrm{H} \cdot$ mechanism is proposed for the subsequent reactions. Transfer of the proton from the amino group of the ligand to the $\mathrm{N}$ atom of quinoline, induced by the H-bonding $\mathrm{C}_{8} \mathrm{H}_{7} \mathrm{~N}---\mathrm{H}_{-} \mathrm{N}^{\mathrm{H}}$ (Int3) and accompanied by an electron transfer from the metal center, generates Int4. Through the H-bonding interaction with the $\mathrm{N}$ atom of the substrate, the amido site not only assists the proton transfer from the $\mathrm{NH}_{3}$ moiety to the $\mathrm{N}$ atom but also directs the hydrogen atom transfer from $\mathrm{Co}(\mathrm{III})-\mathrm{H}$ to the 2-position to furnish 1,2-regioselective reduction.

Based on the deuterium labeling studies, we propose that the 1,2-DHQ product is the intermediate in the transfer hydrogenation of quinolines to THQs ${ }^{16,36,38}$. The conversion of 1,2-DHQ to 1,4-DHQ was not observed under the catalytic conditions, and we speculate that the partially saturated product is further reduced by the "hydride-proton" species through Int2, which is able to transfer the hydride of $\mathrm{Co}(\mathrm{II})-\mathrm{H}$ to the 4-position, and the proton of the amino ligand to the $\mathrm{C}-3$ position ${ }^{20,22}$. This hypothesis is further supported by the transfer hydrogenation of $\mathbf{3 u}$ with the selectively deuterated ammonia boranes (Fig. 9, Supplementary Fig. 3). For the reaction of $3 \mathbf{u}$ with $\mathrm{H}_{3} \mathrm{~N} \cdot \mathrm{BD}_{3}$, the ${ }^{2} \mathrm{H}$ NMR spectrum exhibits only a characteristic ${ }^{2} \mathrm{H}$ signal at $\delta 2.73$ for $d$ $4 \mathbf{u}$, indicating deuterium labeling at the 4-position. In the case of $\mathrm{D}_{3} \mathrm{~N} \cdot \mathrm{BH}_{3}$, deuterium incorporation was found only at the 3position in the desired product, $d-\mathbf{4} \mathbf{u}^{\prime}$. These results also suggest that reversible dehydrogenation of $\mathbf{3} \mathbf{u}$ or $\mathbf{4} \mathbf{u}$ does not occur in the transfer hydrogenations ${ }^{18,20}$.

We have developed a highly efficient transfer hydrogenation system to convert quinolines to 1,2-DHQs. Through cobaltamido cooperation, the $\mathrm{N}$-heteroarene system smoothly undergoes 1,2-reduction by $\mathrm{H}_{3} \mathrm{~N} \cdot \mathrm{BH}_{3}$ which serves as a proton/hydride source. The reaction is conveniently controlled by the use of

\begin{tabular}{|c|c|c|c|}
\hline KIE & $\mathrm{H}_{3} \mathrm{~N} \cdot \mathrm{BD}_{3}$ & $\mathrm{D}_{3} \mathrm{~N} \cdot \mathrm{BH}_{3}$ & $\mathrm{D}_{3} \mathrm{~N} \cdot \mathrm{BD}_{3}$ \\
\hline Cal.(TS1) & 1.67 & 3.57 & 6.01 \\
\hline Cal.(TS2 $\left.{ }_{C 1}\right)$ & 3.21 & 1.36 & 4.35 \\
\hline Cal.(TS1') & 0.50 & 6.09 & 3.06 \\
\hline Exp. & 1.55 & 3.63 & 5.73 \\
\hline
\end{tabular}

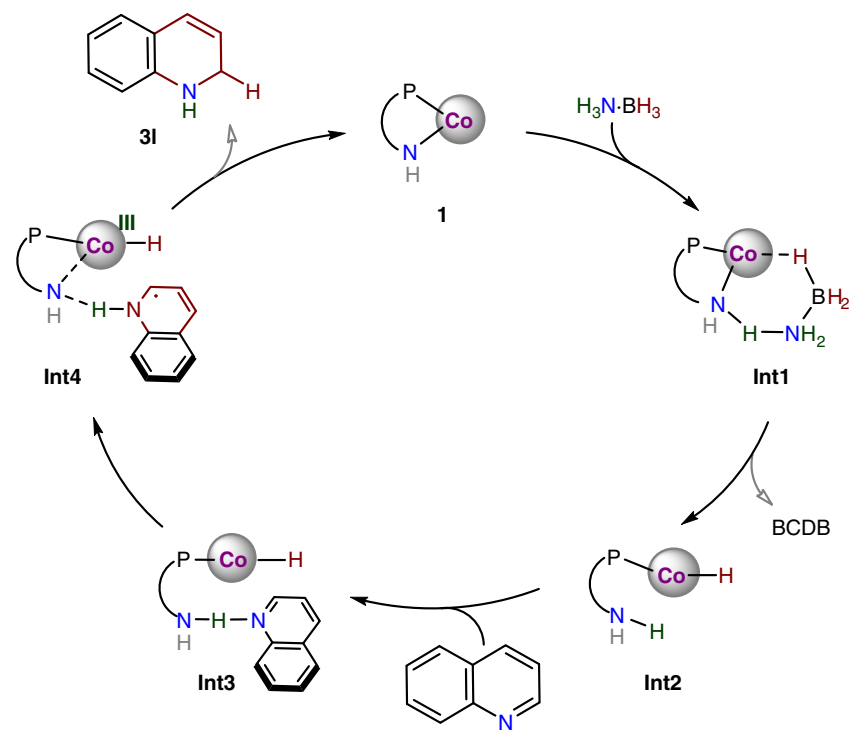

Fig. 8 Proposed Mechanism. Catalytic cycle for partial transfer hydrogenation of quinoline.

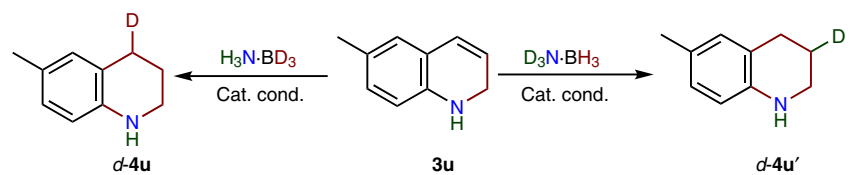

Fig. 9 Deuterium labeling. Reductions of $\mathbf{3} \mathbf{u}$ with deuterated ammonia borane derivatives.

equimolar amounts of reducing agent at room temperature. This catalysis exhibits broad functional group compatibility and enables the large-scale synthesis of 1,2-DHQs. Experimental and theoretical studies reveal that the catalysis invokes a key intermediate, $\mathrm{HCo}-\mathrm{N}^{\mathrm{H}}(\mathrm{H})$ for the hydrogen transfers. The reactive nature of such a "hydride-proton" intermediate is reflected by the dehydrogenation of $\mathrm{H}_{3} \mathrm{~N} \cdot \mathrm{BH}_{3}$, catalyzed by the cobalt-amino complex to release $\mathrm{H}_{2}$ at room temperature. Through H-bonding with the substrate, the amido site is essential in assisting proton transfer and thus directs the 1,2-hydrogenation.

\section{Methods}

Complex 1. $n$-BuLi $(2.5 \mathrm{~mol} / \mathrm{L})(0.29 \mathrm{~mL}, 0.72 \mathrm{mmol})$ was added to a solution of $1,2-\mathrm{Ph}_{2} \mathrm{P}\left(p-\mathrm{CH}_{3} \mathrm{C}_{6} \mathrm{H}_{4}\right) \mathrm{NH}_{2}(210 \mathrm{mg}, 0.72 \mathrm{mmol})$ in THF $(20 \mathrm{~mL})$ at $0{ }^{\circ} \mathrm{C}$. After stirring for $3 \mathrm{~h}$, the solution was allowed to warm to room temperature, and then $[\mathrm{Cp} * \mathrm{CoCl}]_{2}(165 \mathrm{mg}, 0.36 \mathrm{mmol})$ was added. The color of the mixture immediately turned from yellow to rose-Bengal. The solvent was removed under vacuum, and the residue was extracted with hexane $(3 \times 10 \mathrm{~mL})$. After recrystallization from hexane at $-30{ }^{\circ} \mathrm{C}$, compound 1 was obtained as red microcrystals. Yield: $282 \mathrm{mg}$ (81\%). HRMS (m/z): [M] ${ }^{+}$calcd for $\mathrm{C}_{29} \mathrm{H}_{32} \mathrm{CoNP}, 484.1604$; found, 484.1610; analysis (calcd., found for $\mathrm{C}_{29} \mathrm{H}_{32} \mathrm{CoNP}$ ): $\mathrm{C}(71.89,71.68), \mathrm{H}(6.66,6.52), \mathrm{N}$ $(2.89,2.97)$. 
Partial transfer hydrogenation. In a $\mathrm{N}_{2}$-filled glovebox, a scintillation vial (with a magnetic stir bar) was charged with quinoline $(0.5 \mathrm{mmol})$, and $\mathrm{H}_{3} \mathrm{~N} \cdot \mathrm{BH}_{3}(0.55$ $\mathrm{mmol}, 17 \mathrm{mg})$. Then, catalyst $1(1.2 \mathrm{mg}, 2.5 \mu \mathrm{mol})$ and THF $(2 \mathrm{ml})$ were added. The mixture was stirred at $25^{\circ} \mathrm{C}$. After the indicated time, the product was isolated by chromatography on silica gel eluting with EtOAc/petroleum ether.

\section{Data availability}

The X-ray crystallographic coordinates for structures reported in this study have been deposited at the Cambridge Crystallographic Data Centre (CCDC), under deposition numbers 1935438-1935441, 1935443, 1970225 and 1970226. These data can be obtained free of charge from The Cambridge Crystallographic Data Centre via www.ccdc.cam.ac. uk/data_request/cif. All other data supporting the findings of this study are available within the article and Supplementary Information.

Received: 9 January 2020; Accepted: 21 February 2020;

Published online: 06 March 2020

\section{References}

1. Stout, D. M. \& Meyers, A. I. Recent advances in the chemistry of dihydropyridines. Chem. Rev. 82, 223-243 (1982).

2. McSkimming, A. \& Colbran, S. B. The coordination chemistry of organohydride donors: new prospects for efficient multi-electron reduction. Chem. Soc. Rev. 42, 5439-5488 (2013).

3. Bull, J. A., Mousseau, J. J., Pelletier, G. \& Charette, A. B. Synthesis of pyridine and dihydropyridine derivatives by regio- and stereoselective addition to $\mathrm{N}$ activated pyridines. Chem. Rev. 112, 2642-2713 (2012).

4. Zheng, C. \& You, S. L. Transfer hydrogenation with Hantzsch esters and related organic hydride donors. Chem. Soc. Rev. 41, 2498-2518 (2012).

5. Zeng, X., Frey, G. D., Kinjo, R., Donnadieu, B. \& Bertrand, G. Synthesis of a simplified version of stable bulky and rigid cyclic (alkyl)(amino) carbenes, and catalytic activity of the ensuing gold (I) complex in the three-component preparation of 1, 2-dihydroquinoline derivatives. J. Am. Chem. Soc. 131, 8690-8696 (2009).

6. Johnson, W. S. \& Buell, B. G. 1, 2-Dihydroquinoline. J. Am. Chem. Soc. 74, 4517-4520 (1952).

7. Dillard, R. D., Pavey, D. E. \& Benslay, D. N. Synthesis and antiinflammatory activity of some 2, 2-dimethyl-1, 2-dihydroquinolines. J. Med. Chem. 16, 251-253 (1973).

8. Mizoguchi, H., Oikawa, H. \& Oguri, H. Biogenetically inspired synthesis and skeletal diversification of indole alkaloids. Nat. Chem. 6, 57-64 (2014).

9. Engler, T. A., LaTessa, K. O., Iyengar, R., Chai, W. \& Agrios, K. Stereoselective syntheses of substituted pterocarpans with anti-HIV activity, and 5-aza-/5thia-pterocarpan and 2-aryl-2, 3-dihydrobenzofuran analogues. Bioorg. Med. Chem. 4, 1755-1769 (1996).

10. Roche, S. P. \& Porco, J. A. Jr. Dearomatization strategies in the synthesis of complex natural products. Angew. Chem. Int. Ed. 50, 4068-4093 (2011).

11. Kim, B. Y., Ahn, J. B., Hyun, S. H. \& Kang, J. S. Organic electroluminescent material as blue-emitting dopant for organic light emitting device. Repub. Korean Kongkae Taeho Kongbo, KR2013096647A (2013).

12. Hassan, J., Sevignon, M., Gozzi, C., Schulz, E. \& Lemaire, M. Aryl-aryl bond formation one century after the discovery of the Ullmann reaction. Chem. Rev. 102, 1359-1470 (2002).

13. Wedek, V., Van Lommel, R., Daniliuc, C. G., De Proft, F. \& Hennecke, U. Organocatalytic, enantioselective dichlorination of unfunctionalized alkenes. Angew. Chem. Int. Ed. 58, 9239-9243 (2019).

14. Yuan, Y. A., Lu, D. F., Chen, Y. R. \& Xu, H. Iron-catalyzed direct diazidation for a broad range of olefins. Angew. Chem. Int. Ed. 55, 534-538 (2016).

15. Duttwyler, S. et al. Regio- and stereoselective 1,2-dihydropyridine alkylation/ addition sequence for the synthesis of piperidines with quaternary centers. Angew. Chem. Int. Ed. 53, 3877-3880 (2014).

16. Dobereiner, G. E. et al. Iridium-catalyzed hydrogenation of $N$-heterocyclic compounds under mild conditions by an outer-sphere pathway. J. Am. Chem. Soc. 133, 7547-7562 (2011).

17. Adam, R. et al. A general and highly selective cobalt-catalyzed hydrogenation of $\mathrm{N}$-heteroarenes under mild reaction conditions. Angew. Chem. Int. Ed. 56, 3216-3220 (2017).

18. Chakraborty, S., Brennessel, W. W. \& Jones, W. D. A molecular iron catalyst for the acceptorless dehydrogenation and hydrogenation of $\mathrm{N}$-heterocycles. $J$. Am. Chem. Soc. 136, 8564-8567 (2014)

19. Wang, T. et al. Highly enantioselective hydrogenation of quinolines using phosphine-free chiral cationic ruthenium catalysts: scope, mechanism, and origin of enantioselectivity. J. Am. Chem. Soc. 133, 9878-9891 (2011).

20. Baralt, E., Smith, S. J., Hurwitz, J., Horvath, I. T. \& Fish, R. H. Homogeneous catalytic hydrogenation. 6 . synthetic and mechanistic aspects of the regioselective reductions of model coal nitrogen, sulfur, and oxygen heteroaromatic compounds using the ( $\eta^{5}$-pentamethylcyclopentadienyl) rhodium tris(acetonitrile) dication complex as the catalyst precursor. J. Am. Chem. Soc. 114, 5187-5196 (1992).

21. Li, X. et al. Spiro bicyclic bisborane catalysts for metal-free chemoselective and enantioselective hydrogenation of quinolines. Angew. Chem. Int. Ed. 131, 4712-4716 (2019).

22. Mahdi, T. \& Stephan, D. W. Facile protocol for catalytic frustrated Lewis pair hydrogenation and reductive deoxygenation of ketones and aldehydes. Angew. Chem. Int. Ed. 54, 8511-8514 (2015).

23. Lam, J., Szkop, K. M., Mosaferi, E. \& Stephan, D. W. FLP catalysis: main group hydrogenations of organic unsaturated substrates. Chem. Soc. Rev. 48, 3592-3612 (2019)

24. Kim, S., Loose, F., Bezdek, M. J., Wang, X. \& Chirik, P. J. Hydrogenation of Nheteroarenes using rhodium precatalysts: Reductive elimination leads to formation of multimetallic clusters. J. Am. Chem. Soc. 141, 17900-17908 (2019).

25. Wang, Y. et al. Unmasking the ligand effect in manganese-catalyzed hydrogenation: Mechanistic insight and catalytic application. J. Am. Chem. Soc. 141, 17337-17349 (2019).

26. Wang, D. S., Chen, Q. A., Lu, S. M. \& Zhou, Y. G. Asymmetric hydrogenation of heteroarenes and arenes. Chem. Rev. 112, 2557-2590 (2011).

27. Yang, Z. P., Wu, Q. F. \& You, S. L. Direct asymmetric dearomatization of pyridines and pyrazines by iridium-catalyzed allylic amination reactions. Angew. Chem. Int. Ed. 53, 6986-6989 (2014).

28. Meng, W., Feng, X. \& Du, H. Frustrated Lewis pairs catalyzed asymmetric metalfree hydrogenations and hydrosilylations. Acc. Chem. Res. 51, 191-201 (2017).

29. Zhang, J., Chen, F., He, Y. M. \& Fan, Q. H. Asymmetric ruthenium-catalyzed hydrogenation of 2, 6-disubstituted 1, 5-naphthyridines: Access to chiral 1, 5diaza-cis-cecalins. Angew. Chem. Int. Ed. 54, 4622-4625 (2015).

30. Wang, C., Li, C., Wu, X., Pettman, A. \& Xiao, J. pH-Regulated asymmetric transfer hydrogenation of quinolines in water. Angew. Chem. Int. Ed. 48, 6524-6528 (2009)

31. Mai, V. H. \& Nikonov, G. I. Transfer hydrogenation of nitriles, olefins, and Nheterocycles catalyzed by an $N$-heterocyclic carbene-supported half-sandwich complex of ruthenium. Organometallics 35, 943-949 (2016).

32. Wang, Y. et al. Transfer hydrogenation of alkenes using ethanol catalyzed by a NCP pincer iridium complex: scope and mechanism. J. Am. Chem. Soc. 140, $4417-4429$ (2018)

33. Tu, X. F. \& Gong, L. Z. Highly enantioselective transfer hydrogenation of quinolines catalyzed by gold phosphates: achiral ligand tuning and chiral-Anion control of stereoselectivity. Angew. Chem. Int. Ed. 51, 11346-11349 (2012).

34. Guo, Q. S., Du, D. M. \& Xu, J. The development of double axially chiral phosphoric acids and their catalytic transfer hydrogenation of quinolines. Angew. Chem. Int. Ed. 47, 759-762 (2008).

35. Rueping, M. \& Antonchick, A. P. Organocatalytic enantioselective reduction of pyridines. Angew. Chem. Int. Ed. 46, 4562-4565 (2007).

36. Zhou, H. et al. Hydrogenation of quinolines using a recyclable phosphine-free chiral cationic ruthenium catalyst: enhancement of catalyst stability and selectivity in an ionic liquid. Angew. Chem. Int. Ed. 47, 8464-8467 (2008).

37. Park, S. \& Chang, S. Catalytic Dearomatization of N-Heteroarenes with Silicon and Boron Compounds. Angew. Chem. Int. Ed. 56, 7720-7738 (2017).

38. Dudnik, A. S., Weidner, V. L., Motta, A., Delferro, M. \& Marks, T. J. Atomefficient regioselective 1, 2-dearomatization of functionalized pyridines by an earth-abundant organolanthanide catalyst. Nat. Chem. 6, 1100-1107 (2014).

39. Arrowsmith, M., Hill, M. S., Hadlington, T., Kociok-Köhn, G. \& Weetman, C. Magnesium-catalyzed hydroboration of pyridines. Organometallics 30, 5556-5559 (2011)

40. Tamang, S. R., Singh, A., Unruh, D. K. \& Findlater, M. Nickel catalyzed regioselective 1,4-hydroboration of N-heteroarenes. ACS Catal. 8, 6186-6191 (2018).

41. Zhang, F., Song, H., Zhuang, X., Tung, C. H. \& Wang, W. Iron-catalyzed 1, 2 selective hydroboration of $\mathrm{N}$-heteroarenes. J. Am. Chem. Soc. 139, 17775-17778 (2017)

42. Lortie, J. L., Dudding, T., Gabidullin, B. M. \& Nikonov, G. I. Zinc-catalyzed hydrosilylation and hydroboration of $N$-heterocycles. ACS Catal. 7, 8454-8459 (2017).

43. Liu, H., Khononov, M. \& Eisen, M. S. Catalytic 1, 2-regioselective dearomatization of $\mathrm{N}$-heteroaromatics via a hydroboration. ACS Catal. 8 , 3673-3677 (2018).

44. Liu, J. et al. Ni-O cooperation versus nickel(II) hydride in catalytic hydroboration of $N$-heteroarenes. ACS Catal. 9, 3849-3857 (2019).

45. Gandhamsetty, N., Joung, S., Park, S. W., Park, S. \& Chang, S. Boron-catalyzed silylative reduction of quinolines: selective $\mathrm{sp}^{3} \mathrm{C}-\mathrm{Si}$ bond formation. J. Am. Chem. Soc. 136, 16780-16783 (2014).

46. Rao, B., Chong, C. C. \& Kinjo, R. Metal-free regio-and chemoselective hydroboration of pyridines catalyzed by 1, 3, 2-diazaphosphenium triflate. J. Am. Chem. Soc. 140, 652-656 (2018). 
47. Ikariya, T., Murata, K. \& Noyori, R. Bifunctional transition metal-based molecular catalysts for asymmetric syntheses. Org. Biomol. Chem. 4, 393-406 (2006).

48. Peters, R. Cooperative Catalysis: Designing Efficient Catalysts for Synthesis. (Wiley-VCH Verlag, 2015).

49. Wang, D. \& Astruc, D. The golden age of transfer hydrogenation. Chem. Rev. 115, 6621-6686 (2015)

50. Higashi, T., Kusumoto, S. \& Nozaki, K. Cleavage of Si-H, B-H, and C-H bonds by metal-ligand cooperation: focus review. Chem. Rev. 119, 10393-10402 (2019).

51. Drover, M. W., Love, J. A. \& Schafer, L. L. 1, 3-N, O-Complexes of late transition metals. Ligands with flexible bonding modes and reaction profiles. Chem. Soc. Rev. 46, 2913-2940 (2017).

52. Drover, M. W., Schafer, L. L. \& Love, J. A. Capturing $\mathrm{HBCy}_{2}$ : Using N., Ochelated complexes of rhodium (I) and iridium (I) for chemoselective hydroboration. Angew. Chem. Int. Ed. 55, 3181-3186 (2016).

53. Zell, T. \& Milstein, D. Hydrogenation and dehydrogenation iron pincer catalysts capable of metal-ligand cooperation by aromatization/ dearomatization. Acc. Chem. Res. 48, 1979-1994 (2015).

54. Drummond, M. J., Ford, C. L., Gray, D. L., Popescu, C. V. \& Fout, A. R. Radical rebound hydroxylation versus $\mathrm{H}$-atom transfer in non-heme iron (III)-hydroxo complexes: reactivity and structural differentiation. J. Am. Chem. Soc. 141, 6639-6650 (2019).

55. Stahl, T., Müther, K., Ohki, Y., Tatsumi, K. \& Oestreich, M. Catalytic generation of borenium ions by cooperative $\mathrm{B}-\mathrm{H}$ bond activation: the elusive direct electrophilic borylation of nitrogen heterocycles with pinacolborane. $J$. Am. Chem. Soc. 135, 10978-10981 (2013).

56. Omann, L., Königs, C. D. F., Klare, H. F. \& Oestreich, M. Cooperative catalysis at metal-sulfur bonds. Acc. Chem. Res. 50, 1258-1269 (2017).

57. Klare, H. F. et al. Cooperative catalytic activation of $\mathrm{Si}-\mathrm{H}$ bonds by a polar $\mathrm{Ru}$ $-\mathrm{S}$ bond: regioselective low-temperature $\mathrm{C}-\mathrm{H}$ silylation of indoles under neutral conditions by a Friedel-Crafts mechanism. J. Am. Chem. Soc. 133, 3312-3315 (2011).

58. Morris, R. H. Exploiting metal-ligand bifunctional reactions in the design of iron asymmetric hydrogenation catalysts. Acc. Chem. Res. 48, 1494-1502 (2015).

59. Chirik, P. J. Iron- and cobalt-catalyzed alkene hydrogenation: catalysis with both redox-active and strong field ligands. Acc. Chem. Res. 48, 1687-1695 (2015).

60. MacNair, A. J., Millet, C. R., Nichol, G. S., Ironmonger, A. \& Thomas, S. P. Markovnikov-selective, activator-free iron-catalyzed vinylarene hydroboration. ACS Catal. 6, 7217-7221 (2016).

61. Liang, Q., Osten, K. M. \& Song, D. Iron-catalyzed gem-specific dimerization of terminal alkynes. Angew. Chem. Int. Ed. 56, 6317-6320 (2017).

62. Papa, V. et al. Efficient and selective hydrogenation of amides to alcohols and amines using a well-defined manganese-PNN pincer complex. Chem. Sci. 8, 3576-3585 (2017).

63. Elangovan, S. et al. Selective catalytic hydrogenations of nitriles, ketones, and aldehydes by well-defined manganese pincer complexes. J. Am. Chem. Soc. 138, 8809-8814 (2016).

64. Pang, M. et al. Addition of a B-H bond across an amido-cobalt bond: CoII-H-catalyzed hydroboration of olefins. Organometallics 37, 1462-1467 (2018).

65. Fu, S. et al. Ligand-controlled cobalt-catalyzed transfer hydrogenation of alkynes: stereodivergent synthesis of $Z$-and E-alkenes. J. Am. Chem. Soc. 138, 8588-8594 (2016).

66. Han, C. et al. Palladium/Graphitic carbon nitride $\left(\mathrm{g}-\mathrm{C}_{3} \mathrm{~N}_{4}\right)$ stabilized emulsion microreactor as a store for hydrogen from ammonia borane for use in alkene hydrogenation. Angew. Chem. Int. Ed. 57, 14857-14861 (2018).

67. Zhu, X.-Q., Zhang, M.-T., Yu, A., Wang, C.-H. \& Cheng, J.-P. Hydride, hydrogen atom, proton, and electron transfer driving forces of various fivemembered heterocyclic organic hydrides and their reaction intermediates in acetonitrile. J. Am. Chem. Soc. 130, 2501-2516 (2008).

68. Sridharan, V., Suryavanshi, P. A. \& Menendez, J. C. Advances in the chemistry of tetrahydroquinolines. Chem. Rev. 111, 7157-7259 (2011).

69. Kubota, K., Watanabe, Y., Hayama, K. \& Ito, H. Enantioselective synthesis of chiral piperidines via the stepwise dearomatization/borylation of pyridines. $J$. Am. Chem. Soc. 138, 4338-4341 (2016).

70. Ding, J. \& Hall, D. G. Concise synthesis and antimalarial activity of all four mefloquine stereoisomers using a highly enantioselective catalytic borylative alkene isomerization. Angew. Chem. Int. Ed. 52, 8069-8073 (2013).
71. Ding, J., Rybak, T. \& Hall, D. G. Synthesis of chiral heterocycles by ligandcontrolled regiodivergent and enantiospecific Suzuki Miyaura cross-coupling. Nat. Commun. 5, 5474-5482 (2014).

72. Hupe, E., Marek, I. \& Knochel, P. Diastereoselective reduction of alkenylboronic esters as a new method for controlling the stereochemistry of up to three adjacent centers in cyclic and acyclic molecules. Org. Lett. 4, 2861-2863 (2002)

73. Heier, R. F. et al. Synthesis and biological activities of (R)-5, 6-dihydro- $N, N$ dimethyl-4 H-imidazo $[4,5,1-i j]$ quinolin-5-amine and its metabolites. $J$. Med. Chem. 40, 639-646 (1997).

74. Alonso, D. A., Brandt, P., Nordin, S. J. M. \& Andersson, P. G. Ru(arene) (amino alcohol)-catalyzed transfer hydrogenation of ketones: mechanism and origin of enantioselectivity. J. Am. Chem. Soc. 121, 9580-9588 (1999).

75. Yamakawa, M., Yamada, I. \& Noyori, R. CH/ $\pi$ attraction: the origin of enantioselectivity in transfer hydrogenation of aromatic carbonyl compounds catalyzed by chiral $\eta^{6}$-arene-ruthenium(II) complexes. Angew. Chem. Int. Ed. 40, 2818-2821 (2001).

76. Yang, X., Zhao, L., Fox, T., Wang, Z.-X. \& Berke, H. Transfer hydrogenation of imines with ammonia-borane: a concerted double-hydrogen-transfer reaction. Angew. Chem. Int. Ed. 49, 2058-2062 (2010)

77. Sebastian, K. \& Shaik, S. How to conceptualize catalytic cycles? The energetic span model. Acc. Chem. Res. 44, 101-110 (2011).

\section{Acknowledgements}

We thank the Natural Science Foundation of China (21871166 and 21873031) and Natural Science Foundation of Shandong Province (ZR2019ZD45) for their financial support.

\section{Author contributions}

W.W., M.P., and C.-H.T. conceived and designed the project. M.P. S.Z., and W.W. conducted the experiments and analyzed the data. J.-Y.C. and R.-Z.L. carried out the computational analyses. W.W. and R.-Z.L. wrote the manuscript. All authors provided comments on the experiments and the manuscript during its preparation.

\section{Competing interests}

The authors declare no competing interests.

\section{Additional information}

Supplementary information is available for this paper at https://doi.org/10.1038/s41467020-15118-x.

Correspondence and requests for materials should be addressed to R.-Z.L. or W.W.

Peer review information Nature Communications thanks Sukbok Chang and the other, anonymous, reviewer(s) for their contribution to the peer review of this work.

Reprints and permission information is available at http://www.nature.com/reprints

Publisher's note Springer Nature remains neutral with regard to jurisdictional claims in published maps and institutional affiliations.

Open Access This article is licensed under a Creative Commons Attribution 4.0 International License, which permits use, sharing, adaptation, distribution and reproduction in any medium or format, as long as you give appropriate credit to the original author(s) and the source, provide a link to the Creative Commons license, and indicate if changes were made. The images or other third party material in this article are included in the article's Creative Commons license, unless indicated otherwise in a credit line to the material. If material is not included in the article's Creative Commons license and your intended use is not permitted by statutory regulation or exceeds the permitted use, you will need to obtain permission directly from the copyright holder. To view a copy of this license, visit http://creativecommons.org/ licenses/by/4.0/.

(c) The Author(s) 2020 